\title{
DSH NEWS
}

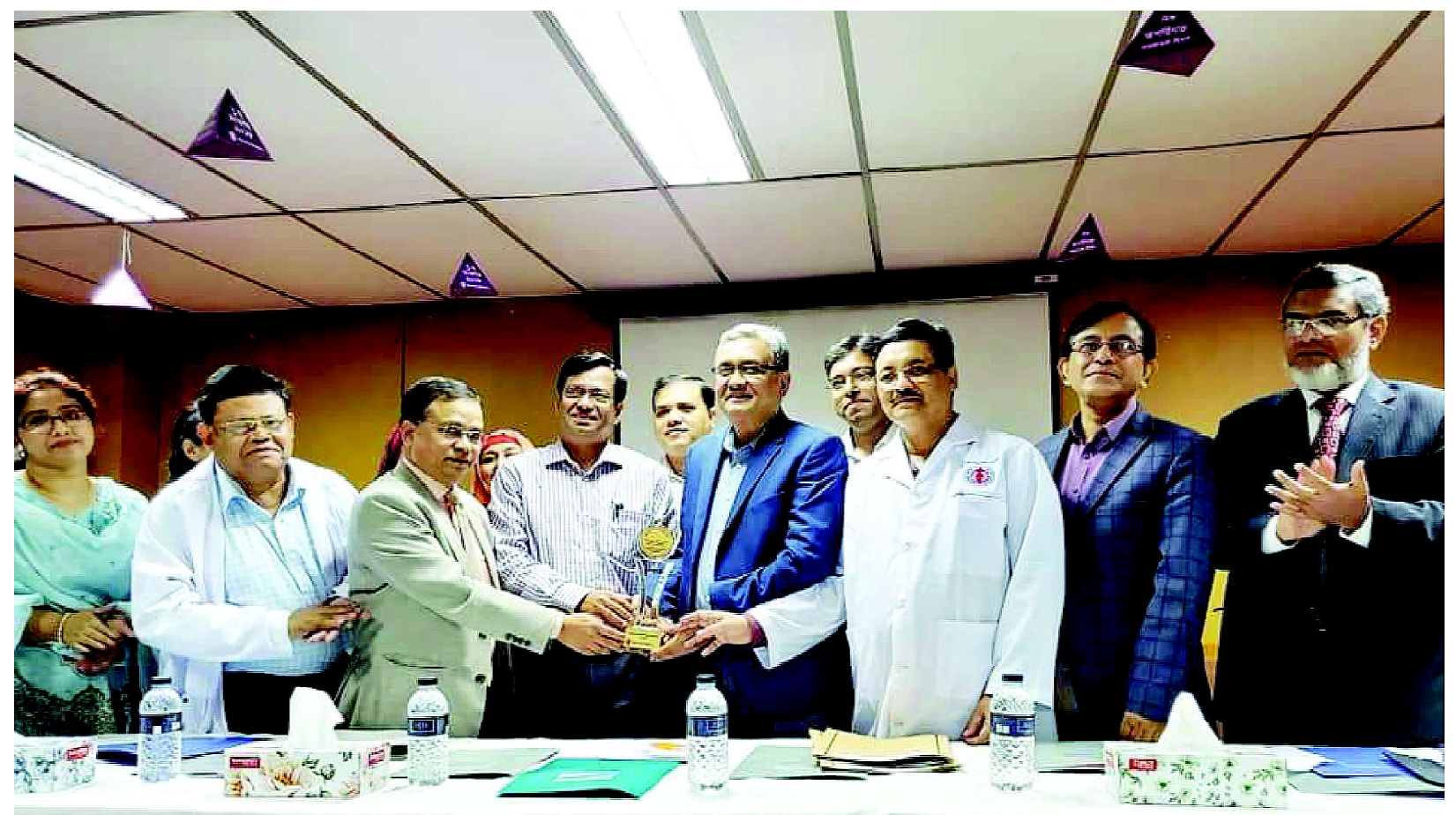

Fig 1 Observence of World Premature Day 2019 and giving honor to Prof. MAK Azad Chowdhury, Head of Neonatal Medicine, BICH and Dhaka Shishu Hospital as a pioneer of kangaroo mother care in Bangladesh.

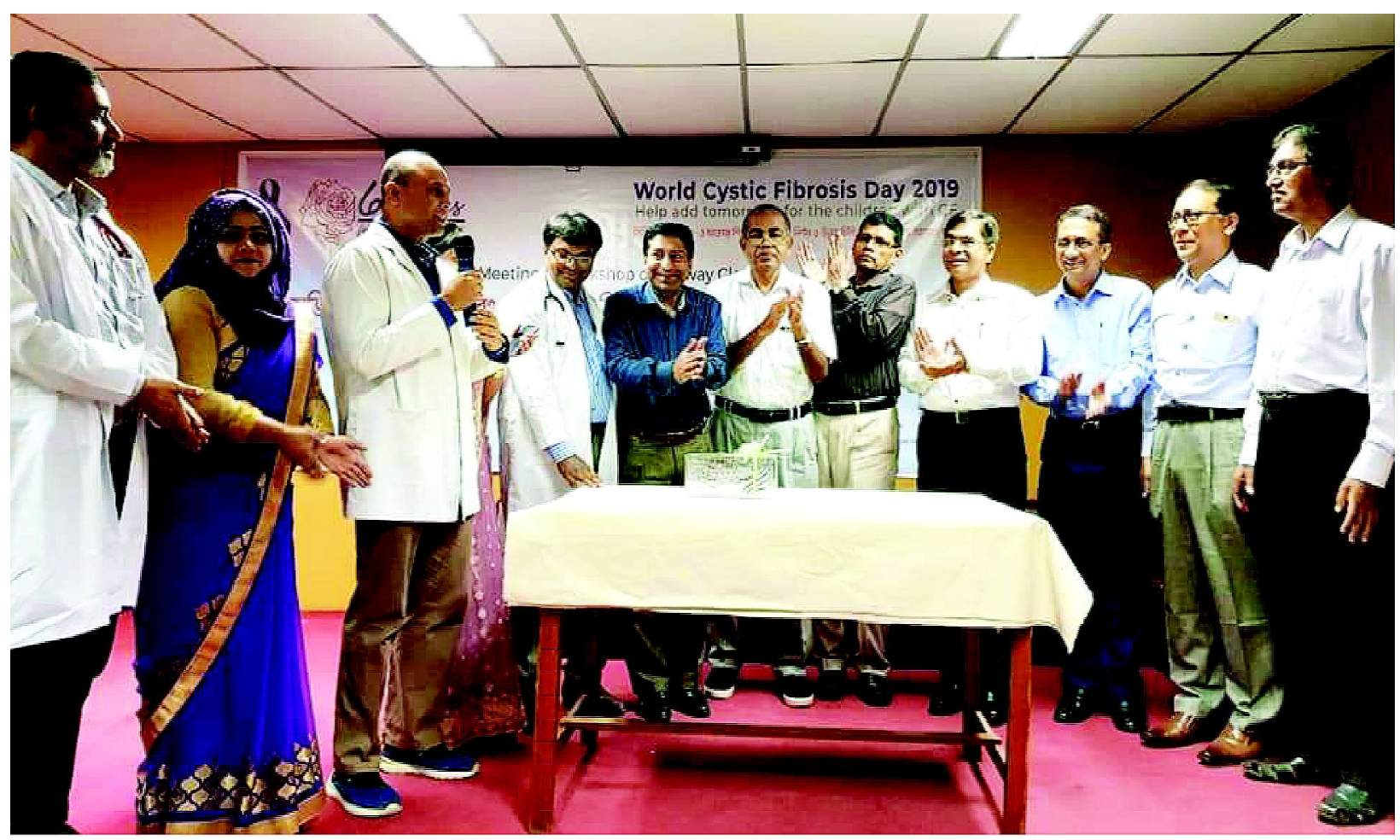

Fig 2 Observence of World Cystic Fibrosis Day 2019 


\section{BICH NEWS}

$\mathrm{BICH}$ is the academic wing of Dhaka Shishu Hospital. It was established in $30^{\text {th }}$ January, 1983. It is affiliated with Dhaka University, Bangabandhu Sheikh Mujib Medical University (BSMMU) and Bangladesh College of Physicians and Surgeons (BCPS). It has been conducting different courses e.g. DCH, FCPS, MD Paediatrics, MS Paediatric surgery \& B.Sc in Health technology. It also conducts different sub-specialty courses e.g. FCPS Neonatology, FCPS Haemato-oncology, FCPS Nephrology, MD Neonatology, MD Haematooncology and MD Nephrology. It conducts 3 months certificate course in Paediatrics and 15 days Intensive course for MCPS. It organizes IMCI training and Palli Shishu Rural Health Training. Apart from this, the Institute also runs its regular academic activities. It has established Basic Science Department since 2006.
Diploma course of paediatric nursing has been started from 1st January 2012 and Diploma in paediatric physiotherapy under process.

\section{Library facilities}

The library of $\mathrm{BICH}$ has a rich collection of updated medical texts and reference books and reputed Medical Journals of home and abroad. BICH has introduced Broad Band facilities which are open to all students, teachers/ consultants of hospital for 24 hours. Facilities of library are also improved by HINARI. Students can download 2230 Medical Journals \& more than 50 Paediatric Journals.

\section{Present News}

A newly formed classroom in BICH has been named as Prof. Sultan Ahmed Chowdhury as a tribute to First Honarary Director of Dhaka Shishu Hospital. 